\title{
Refinement of a clearing protocol to study crassinucellate ovules of the sugar beet (Beta vulgaris L., Amaranthaceae)
}

\author{
Monika Kwiatkowska', Dariusz Kadłuczka², Maria Wędzony ${ }^{3}$, Beata Dedicova ${ }^{4}$ and Ewa Grzebelus²*
}

\begin{abstract}
Background: Clearing methods allow relatively quick processing of plant material and examination of cellular structures by rendering tissues and organs translucent. They have been adapted for plant embryology, primarily to study ovule development, megasporogenesis, megagametogenesis and embryogenesis. Such clearing methods overcome several disadvantages of the conventional embedding-sectioning techniques that are arduous and time-consuming. Although numerous protocols with different clearing solutions have been described, there have been no reports to date proposing a reliable method to clear the crassinucellate ovules of the sugar beet (Beta vulgaris L.), an economically important crop. Therefore, this study aims to find a suitable approach to improve the tissue transparency of sugar beet ovules at different developmental stages.

Results: We established a methyl salicylate-based protocol that significantly improved the transparency of the $B$. vulgaris ovule structures, which allowed us to observe the megagameto- and embryogenesis of that species. This was achieved by (1) chemical softening of the tissues; (2) vacuum pump-assisted infiltration step; (3) shaking-assisted incubation with clearing mixtures; and (4) manual removal of the chemically softened seed coat.

Conclusions: The effectiveness of our method is due to the strategy combining various approaches at different stages of the procedure aiming at increasing the accessibility of the internal ovule structures to the clearing solution. The results of this study may be applied in sugar beet breeding programs, and it will provide a basis for further investigation of numerous aspects of the species' embryology. Moreover, that unique approach may be easily adapted to other species developing crassinucellate ovules.
\end{abstract}

Keywords: Differential interference contrast (DIC), Embryogenesis, Megagametogenesis, Methyl salicylate, Plant embryology

\section{Background}

The sugar beet (Beta vulgaris L., Amaranthaceae) belongs to crops of great economic importance due to its storage root, which accumulates sucrose in high concentration. It is mostly grown for sugar production but it also serves as a source of bioethanol and a component of animal feed [1]. Developing new varieties is frequently based on homozygous lines which are produced by

\footnotetext{
*Correspondence: e.grzebelus@urk.edu.pl

${ }^{2}$ Institute of Plant Biology and Biotechnology, Faculty of Biotechnology and Horticulture, University of Agriculture in Krakow, 29 Listopada 54,

31-425 Kraków, Poland

Full list of author information is available at the end of the article
}

haploid/doubled haploid techniques [2]. Despite decades of studies, doubled haploid lines of sugar beet are obtained exclusively with one method, i.e. by gynogensis in vitro induction, in isolated ovule cultures. Haploids are induced at low frequency and their genome needs doubling before their practical application [3, 4]. An accessible and simple analysis of ovule structures could be a very valuable tool in precise and fast screening of induced in vitro gynogenesis, enabling fast evaluation of new induction protocols and evaluation of various genotype responses to new treatments.

The clearing technique is a well-known and appreciated method in plant embryology. It allows rapid observation 
of ovule structures at different stages of development including both sporophytic tissues and gametophytic cell lines. Since clearing protocols are relatively easy and enable reducing the number of steps in material preparation $[5,6]$, they are advantageous over the conventional embedding-sectioning procedures that are excessively laborious and time-consuming. The latter are especially tedious in research as they require analysis of numerous samples. Moreover, embedding-sectioning techniques make analysis difficult to interpret because three-dimensional structures are frequently distributed over several sections and thus a reconstruction of the full image is necessary [7, 8]. Nonetheless, chemical treatmentalthough effective for clearing-renders plant tissues and organs fragile. Therefore, spacers between the slide and the coverslip are often applied to avoid compressing the cleared sample [5, 9].

Over the years, clearing techniques have been used in various categories of plant research, especially in classical embryology. They were primarily applied to investigate the sexual reproduction of plants: in the analysis of anther development, microsporogenesis, microgametogenesis, pollen and pollen tube growth, ovule ontogeny, megasporogenesis, megagametogenesis, and embryogenesis [5, 10-14]. These methods are also important tools in the research on apomixis $[6,13,15-18]$. Additionally, clearing techniques are useful in studies on plant anatomy, e.g. on the structure of plant vascular system [19-21] and in experimental embryology, e.g. to analyze the development of embryos resulting from intergeneric crosses [22].

All clearing procedures are based on equilibration of the refractive index throughout the sample in order to reduce inhomogeneities in light scatter [23]. There are many clearing solutions that make maternal tissues translucent, enabling analysis of the gametophytic structures in pre-fertilization stages of the ovule development and the early sporophyte development [24]. One of the most commonly used clearing mixture was introduced by Herr [5]. It is composed of lactic acid, chloral hydrate, phenol, clove oil and xylene. Application of methyl salicylate as a clearing agent is another common approach introduced by Crane [25] and further modified by Young et al. [6]. Other procedures use various oxidative bleaches, such as hypochlorite [19], hydrogen peroxide [26], chlorine [27], and chromium trioxide [28]. Hoyer's solution [29], lactophenol [30], dibutyl phthalate in combination with benzyl benzoate [15], Visicol ${ }^{\mathrm{TM}}$ [31], and more have been developed for various specific purposes. The result of a particular clearing method depends on its interaction with the studied plant tissue. Because tissue chemistry, cell sizes and their density all diverge from object to object and among different species, each clearing method should be carefully adjusted to the examined plant material. This aspect is especially important in embryology, where massive maternal tissue often surrounds generative cells, as observed in B. vulgaris ovules.

For decades, various aspects of beet embryology and reproductive biology have been investigated using embedding-sectioning techniques for light or electron microscopy. The aspects in question include ovule and embryo sac ultrastructure [32-34], gynogenic embryos development by in vitro techniques [2, 4, 35-41], seed development and germination [42] as well as apomictic embryo development through aposporic embryo sac formation, parthenogenesis or adventitious embryony [43]. However, the analysis of reproductive processes in the sugar beet has been very difficult due to the specific structure of its crassinucellate and bitegmic ovules including: (1) the formation of micropyle by the massive inner integument, (2) the development of the nucellar cap by the periclinal divisions of the apical cells in the nucellar epidermis, that elongate and become richly protoplasmic, (3) the formation of 5-6 layers of parietal cells above the sporogenous cell, (4) the deep position of the developing embryo sac in the nucellar tissue, (5) the outer epidermis of the testa-a mechanical layer with strongly thickened outer walls, saturated with tannins, (6) the thick seed coat formed by both integuments saturated with tannins, and (7) the exotestal arillate seed with the long curved embryo, surrounded by a thin layer of endosperm and a massive starchy perisperm [44-46], cited after [47, 48]. Moreover, during the flower development, ovules keep changing their position, which hinders the proper orientation of the specimen during conventional embedding in the supporting matrices. As a consequence, a large amount of improperly cut ovules cannot be correctly analyzed, which results in substantial material losses. It should be emphasized that such difficulties do not occur in the clearing of tenuinucellate ovules, as exemplified by the model plant Arabidopsis thaliana [49-51], Rudbeckia bicolor [52], Taraxacum atricapillum [53] as well as in other crassinucellate ovules, especially those with a relatively small amount of nucellus cells, e.g. Agave tequilana [54], Cenchrus ciliaris [6], Paspalum rufum [55], Ranunculus auricomus [56]. Therefore, here for the first time, we report a successful methyl salicylatebased method for clearing of crassinucellate sugar beet ovules at different stages of their development allowing unambiguous visualization of ovule structures, the gametophyte and the embryo development. We believe, that this protocol may also be helpful in embryological studies on other crop species with the same or similar anatomical ovule structure, such as Chenopodium quinoa [57], Papaver somniferum [58], Spinacia oleracea [59], 
Amaranthus caudatus-called the crop of the XXI century [60], and others.

\section{Methods}

Plant material

To improve the clearing procedure, ovules of Beta vulgaris (breeding lines L365 and LY64, Syngenta Seeds AB, Sweden) at different stages of development were used. Additionally, for comparison purposes, tenuinucellate ovules of the model plant Arabidopsis thaliana L. and Biscutella laevigata $\mathrm{L}$. as well as other crassinucellate ovules of Armeria maritima (Milld.) Willd. and Viola banksii K.R. Thiele \& Prober were subjected to the same clearing protocol.

The flowers of $B$. vulgaris and A. thaliana were collected from seed-produced plants. The seeds of $B$. vulgaris were treated against seed borne diseases by 5 -min incubation in $57^{\circ} \mathrm{C}$ water bath before planting into sowing soil Emmaljunga I (Emmaljunga Torvmull AB, Sweden). The seedlings were grown in $1-\mathrm{L}$ pots in a climate chamber at $18 / 12{ }^{\circ} \mathrm{C}$ (day/night) with a 22 -h photoperiod in the light with the intensity of $90 \mu \mathrm{mol} \mathrm{m} \mathrm{m}^{2}$, with additional $\mathrm{CO}_{2}$ enrichment at the concentration of $400 \mathrm{ppm}$ and $60-70 \%$ of relative humidity. After 3-4 weeks the plants with 6-8 leaves were transferred into a vernalization chamber at $6-9{ }^{\circ} \mathrm{C}$, with a 12 -h photoperiod in the light with the intensity of $70 \mu \mathrm{mol} \mathrm{m} \mathrm{s}^{-1}$. After a 14-week vernalization period, well developed plants with 8-10 leaves were re-planted into 2-L pots with planting soil Emmaljunga II (Emmaljunga Torvmull $\mathrm{AB}$, Sweden) and grown in a climate chamber at $18 / 16^{\circ} \mathrm{C}$ (day/night) with a 18-h photoperiod in the light with the intensity of $480-500 \mu \mathrm{mol} \mathrm{m} \mathrm{m}^{-1}$ (metal halide lamp bulbs $400 \mathrm{~W}$ GE Kolorarc, Hungary), with additional $\mathrm{CO}_{2}$ enrichment at the concentration of $600 \mathrm{ppm}$ and $60-70 \%$ of relative humidity. Approximately $6-8$ weeks later, the flowers were collected.

The seeds of $A$. thaliana were sown to a moss-sandy substrate (Hollas, Poland) and incubated in a climate room at $20 \pm 2{ }^{\circ} \mathrm{C}$ with a 16 -h photoperiod in the light with the intensity of $40 \mu \mathrm{mol} \mathrm{m} \mathrm{m}^{-2} \mathrm{~s}^{-1}$ for germination and plant growth. About 10 weeks later, the flowers of $A$. thaliana were collected.

The flowers of B. laevigata and A. maritima were collected from their natural habitat in Bolesław (Poland), while the flowers of $V$. banksii were obtained from the collection of the Department of Plant Cytology and Embryology, Jagiellonian University (Krakow, Poland).

\section{Ovule treatment and image acquisition}

All flowers were fixed in FAA (38\% formaldehyde/glacial acetic acid/70\% ethanol; 6:4:90, v/v) for $48 \mathrm{~h}$, and stored in $70 \%$ ethanol in $4{ }^{\circ} \mathrm{C}$ until further use. Ovules at different developmental stages, in ovaries or dissected from ovaries, were dehydrated in a graded ethanol series $(70 \%, 95 \%, 100 \%-1 \mathrm{~h}$ each). After the $95 \%$ ethanol solution, the ovules in pre-fertilization stages were incubated in eosin ( $2 \%$ solution in $95 \%$ ethanol, w/v) for $1 \mathrm{~h}$ to improve their visibility during further processing. Then the ovules were cleared initially with methyl salicylate, according to Young et al. [6], with minor modifications after Musiał et al. [53], involving an additional step of treatment with the clearing solution, and modified incubation time. In detail, the infiltration procedure was performed as follows: (1) the ovules were treated with a mixture of $100 \%$ ethanol and methyl salicylate in proportions of $3: 1,1: 1,1: 3$ (1.5 $\mathrm{h}$ each), and then (2) incubated with pure methyl salicylate for $24 \mathrm{~h}$-hereinafter referred to as the standard procedure-or (3) with prolonged incubation time, of up to 4 weeks (Table 1 ). In order to improve the tissue transparency in B. vulgaris ovules, numerous modifications of the standard procedure were tested, including the use of macerating agents (such as inorganic acids of different concentrations, i.e. 0.1 or $1 \mathrm{M}$ $\mathrm{HCl}, 3$ or $95 \% \mathrm{H}_{2} \mathrm{SO}_{4}, 1 \% \mathrm{H}_{5} \mathrm{IO}_{6}$ ), and other chemicals, such as Schiff's reagent consisting of $1 \%(\mathrm{w} / \mathrm{v})$ basic fuchsin and $2,3 \%(\mathrm{w} / \mathrm{v}) \mathrm{K}_{2} \mathrm{~S}_{2} \mathrm{O}_{5}$ in $0.15 \mathrm{M} \mathrm{HCl}$, and 3 or $6 \%$ (v/v) hydrogen peroxide-both separately and combined. The manipulation of the incubation time of the material in the solutions was combined with an application of the vacuum pump (Concentrator plus, Eppendorf, Hamburg, Germany) and orbital shaker (150 rpm), or mechanical tissue disruption using a syringe needle, all in order to

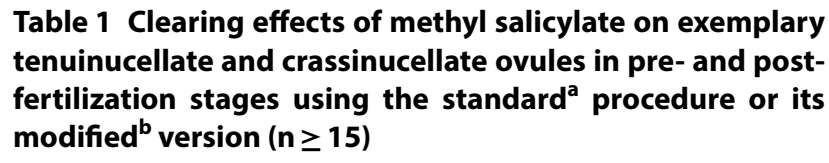
modified $^{\text {b }}$ version $(n \geq 15)$

\begin{tabular}{|c|c|c|c|}
\hline Ovule type & Species & $\begin{array}{l}\text { Clearing } \\
\text { procedure }\end{array}$ & Clearing effect \\
\hline \multirow[t]{2}{*}{ Tenuinucellate } & \multirow{2}{*}{$\begin{array}{l}\text { Arabidopsis } \\
\text { thaliana }^{\mathrm{d}}\end{array}$} & Standard & + \\
\hline & & Modified & ++ \\
\hline \multirow[t]{5}{*}{ Crassinucellate } & $\begin{array}{l}\text { Biscutella laevi- } \\
\text { gata }\end{array}$ & Standard & + \\
\hline & Armeria maritima & Standard & + \\
\hline & Viola banksii & Standard & + \\
\hline & Beta vulgaris & Standard & - \\
\hline & & Modified & - \\
\hline \multicolumn{4}{|c|}{$\begin{array}{l}\text { a The standard procedure: absolute ethanol : methyl salicylate, in proportions of } \\
3: 1,1: 1,1: 3,0: 1 \text { (1.5 } \mathrm{h} \text { each change) }\end{array}$} \\
\hline \multicolumn{4}{|c|}{$\begin{array}{l}\mathrm{b} \text { The modified procedure: as the standard, except the step of clearing in pure } \\
\text { methyl salicylate, which was prolonged from } 24 \mathrm{~h} \text { to } 4 \text { weeks }\end{array}$} \\
\hline \multicolumn{4}{|c|}{$\begin{array}{l}{ }^{c}(++) \text { very well cleared ovules; }(+) \text { ovules cleared at an acceptable level; }(-) \\
\text { ovules cleared at an unsatisfactory level }\end{array}$} \\
\hline \multicolumn{4}{|c|}{$\begin{array}{l}{ }^{d} \text { The whole ovaries were cleared to prevent the material loss during its } \\
\text { preparing process }\end{array}$} \\
\hline
\end{tabular}


improve tissue penetration by the clearing solution. All the steps in these modified procedures and the remarks on them are shown in detail in Additional file 1: Table S1. The best approaches were selected and applied to further studies (Table 2). The cleared ovules were prepared on microscope slides under a dissecting microscope, in a drop of methyl salicylate, according to Herr [5]. The slides were examined using differential interference contrast

Table 2 The optimized protocols for improved clearing efficacy in crassinucellate ovules of B. vulgaris ( $\mathbf{n} \geq 15)$

\begin{tabular}{|c|c|c|c|}
\hline \multirow[t]{2}{*}{ Ovule development } & \multicolumn{2}{|l|}{ Tissue processing } & \multirow[t]{2}{*}{ Notes } \\
\hline & Treatment & Conditions $^{\mathrm{a}}$ & \\
\hline \multirow[t]{9}{*}{ Pre-fertilization stages ${ }^{\mathrm{b}}$ (protocol I) } & Rehydration ${ }^{c}$ & On an orbital shaker ${ }^{d}$ & $1,2,3$ \\
\hline & $1 \mathrm{M} \mathrm{HCl}$ & $5 \mathrm{~min}$ & \\
\hline & $1 \mathrm{M} \mathrm{HCl}$ & $60^{\circ} \mathrm{C}, 10 \mathrm{~min}$ & \\
\hline & $1 \mathrm{M} \mathrm{HCl}$ & $5 \mathrm{~min}$ & \\
\hline & Schiff's reagent & $30 \mathrm{~min}$, in the dark & \\
\hline & Sulfur water ${ }^{\mathrm{e}}$ & $3 \times 10 \mathrm{~min}$ & \\
\hline & $d \mathrm{H}_{2} \mathrm{O}$ & $3 \times 5 \min$ & \\
\hline & Dehydration $^{f}$ & On an orbital shaker & \\
\hline & Clearing $^{g}$ & On an orbital shaker, with vacuum treatment ${ }^{h}$ & \\
\hline \multirow[t]{12}{*}{ Post-fertilization stages (protocol II) } & Rehydration & On an orbital shaker & 2,4 \\
\hline & $95 \% \mathrm{H}_{2} \mathrm{SO}_{4}$ & $5 \mathrm{~min}$ & \\
\hline & $d \mathrm{H}_{2} \mathrm{O}$ & $5 \mathrm{~min}$ & \\
\hline & $1 \mathrm{M} \mathrm{HCl}$ & $5 \mathrm{~min}$ & \\
\hline & $1 \mathrm{M} \mathrm{HCl}$ & $60^{\circ} \mathrm{C}, 10 \mathrm{~min}$ & \\
\hline & $1 \mathrm{M} \mathrm{HCl}$ & $5 \mathrm{~min}$ & \\
\hline & Schiff's reagent & $30 \mathrm{~min}$ & \\
\hline & Sulfur water & $3 \times 10 \min$ & \\
\hline & $d \mathrm{H}_{2} \mathrm{O}$ & $3 \times 5 \min$ & \\
\hline & Dehydration & On an orbital shaker & \\
\hline & Clearing & On an orbital shaker, with vacuum treatment & \\
\hline & Manual removal of the seed coat & & \\
\hline \multirow[t]{8}{*}{ Post-fertilization stages (protocol III) } & Rehydration & On an orbital shaker & $4,5,6$ \\
\hline & $95 \% \mathrm{H}_{2} \mathrm{SO}_{4}$ & $5 \mathrm{~min}$ & \\
\hline & $d \mathrm{H}_{2} \mathrm{O}$ & $5 \mathrm{~min}$ & \\
\hline & $3 \% \mathrm{H}_{2} \mathrm{SO}_{4}$ & $60^{\circ} \mathrm{C}, 90 \mathrm{~min}$ & \\
\hline & $d \mathrm{H}_{2} \mathrm{O}$ & $3 \times 5 \min$ & \\
\hline & Dehydration & On an orbital shaker & \\
\hline & Clearing & On an orbital shaker, with vacuum treatment & \\
\hline & Manual removal of the seed coat & & \\
\hline
\end{tabular}

1. The tissue transparency was significantly improved

2. Schiff's reagent stained ovules making the tissues visible-eosin treatment may be omitted

3. Longer than 24-h incubation in pure methyl salicylate improved the tissue transparency

4. The tissue transparency was improved due to the removable seed coat, caused by the use of $\mathrm{H}_{2} \mathrm{SO}_{4}$

5. In the case of ovules in pre-fertilization stages, maceration in concentrated sulfuric acid may be omitted

6. Protocols II and III may be used interchangeably, since both gave the same clearing results

a All the steps were performed at room temperature, unless otherwise specified

$\mathrm{b}$ The whole ovaries were cleared to prevent the material loss during its preparation process

c Rehydration = ethanol: 70\%, 50\%, 30\%; $d \mathrm{H}_{2} \mathrm{O}$ (5 min each)

d Parameters of shaking were set at $150 \mathrm{rpm}$

e Sulfur water was made with $5 \mathrm{mg} \mathrm{mL}^{-1} \mathrm{~K}_{2} \mathrm{~S}_{2} \mathrm{O}_{5}$ in $0.05 \mathrm{M} \mathrm{HCl}$

f Dehydration = ethanol: 10\%, 30\%, 50\%, 70\% (15 min each); $95 \%, 100 \%$ ( $1 \mathrm{~h} \mathrm{each}$ )

${ }^{g}$ Clearing $=100 \%$ ethanol: methyl salicylate, in proportions of 3:1, 1:1, 1:3 ( $2 \mathrm{~h}$ each change); pure methyl salicylate (at least $24 \mathrm{~h}$ )

h After $1 \mathrm{~h}$ of each change of the clearing solution, vacuum treatment for $5 \mathrm{~min}$ was applied 
(DIC) optics under an Axio Imager.M2 microscope (Carl Zeiss, Göttingen, Germany) equipped with an AxioCam MRm camera (Carl Zeiss, Göttingen, Germany), and processed with AxioVision 4.8 (Carl Zeiss MicroImaging) and Adobe ${ }^{\circledR}$ Photoshop ${ }^{\circledR}$ CS3 (Adobe Systems) software. Over 15 ovules per protocol variant were examined. The ovule structure as well as megagametogenesis and embryogenesis were analyzed.

\section{Results}

The standard clearing procedure applied to the tenuinucellate ovules of Arabidopsis thaliana and Biscutella laevigata resulted in a satisfactory level of their structures' transparency (Table 1), as observed for all the analyzed ovules. The application of eosin before tissue clearing improved the visibility of small structures, preventing material loss during preparation, while it did not negatively interfere with microscopic observations. Regardless of the developmental stages of the examined ovules, the tissues were very well cleared, and both sporophytic and gametophytic cells were clearly visible (Additional file 2: Fig. S1; Additional file 3: Fig. S2b). The only exceptions were $A$. thaliana ovules at globular- and heart-shaped embryo stages, where the developing seed coat somewhat hampered the penetration of methyl salicylate causing insufficient tissue transparency (Additional file 2: Fig. S1d). In this case, the increase in the incubation time in pure methyl salicylate to as many as 4 weeks contributed to improved transparency of the ovule structures which were better cleared, compared to the standard procedure (Fig. 1). The standard procedure on the crassinucellate ovules of Armeria maritima and Viola banksii resulted in effectively cleared embryo sac cells in all the analyzed ovules (Table 1; Additional file 3: Fig. S2a, c). Conversely, this procedure was unsuccessful for the crassinucellate ovules of Beta vulgaris, both in early and late stages of development, resulting in tissues that were not transparent enough to make observations. The visibility of the generative cells was unsatisfactory, and the female gametophyte was only slightly visible (Fig. 2a). Also, the prolonged time of the methyl salicylate treatment did not result in any improvement in the clearing of B. vulgaris ovules (Fig. 2b).

All other modifications and the remarks on them are listed in Additional file 1: Table S1, showing the detailed procedures which were tested on sugar beet ovules in the present study. Among these, mechanical tissue disruption using a syringe needle, aimed at opening the ovule structure and facilitating penetration of the clearing mixtures did not succeed due to the small size of the ovules and an increased risk of damaging the female gametophyte. Moreover, this treatment resulted in low-quality images (Fig. 2d). Other attempts were based on the use of post-clearing treatments with some macerating agents (3\% hydrogen peroxide, $3 \%$ sulfuric acid), but they did not improve the transparency of the ovule tissues. Furthermore, several chemicals were used before the clearing step, such as $1 \%$ orthoperiodic acid, $0.1 \mathrm{M}$ hydrochloric acid, both combined with Schiff's reagent, $6 \%$ hydrogen peroxide and $3 \%$ sulfuric acid (Fig. 2e-i), of which only the application of the hydrochloric acid with Schiff's reagent systematically brought better results, exclusively in the case of young ovules (Fig. 2h). The application of shaking and vacuuming treatment during infiltration steps was another promising variant regularly improving the transparency of the ovule tissue (Fig. 2c).

From the modifications of the standard procedure, we selected those that significantly improved the transparency of $B$. vulgaris ovule structures (Table 2, whereby the procedures were divided based on the stage of ovule development into pre- and post-fertilization stages, which was accompanied by the absence or presence of the seed coat, respectively). Such an improvement was achieved by novel, never previously applied, combinations of various approaches at different stages of the procedure. Firstly, the use of vacuum pump to infiltrate the material with methyl salicylate mixtures, and the fact that the clearing step was performed with continuous shaking, rendered the penetration of the relatively dense clearing solution much more effective. Secondly, both the ovules before fertilization and the developing seeds were treated with hydrochloric acid (1 M $\mathrm{HCl})$ in $60{ }^{\circ} \mathrm{C}$ combined with Schiff's reagent, causing their softening. Thirdly, the ovules in post-fertilization stages (developing seeds) were pre-treated with highly concentrated sulfuric acid $\left(95 \% \mathrm{H}_{2} \mathrm{SO}_{4}\right)$, which made it possible to remove the seed coats, increasing the accessibility of the internal tissues to the clearing solution. If concentrated sulfuric acid was not used, even at very young stages of embryogenesis, the developing hard seed coat hindered the clarity and transparency of ovule tissues, even after applying maceration procedure before clearing (Fig. 3a). Thus, by applying these combined approaches, B. vulgaris ovule tissues systematically showed a satisfactory level of transparency, allowing observation of the developing embryo sacs and embryos (Fig. 3b-f). Additionally, the material hydrolyzed by hydrochloric acid was exposed to further reaction with Schiff's reagent, which stained it reddish pink, preventing the loss of small objects. For clarity, a schematic diagram illustrating the structure of the crassinucellate ovules of $B$. vulgaris at pre- and postfertilization stages is included in Fig. 4. 

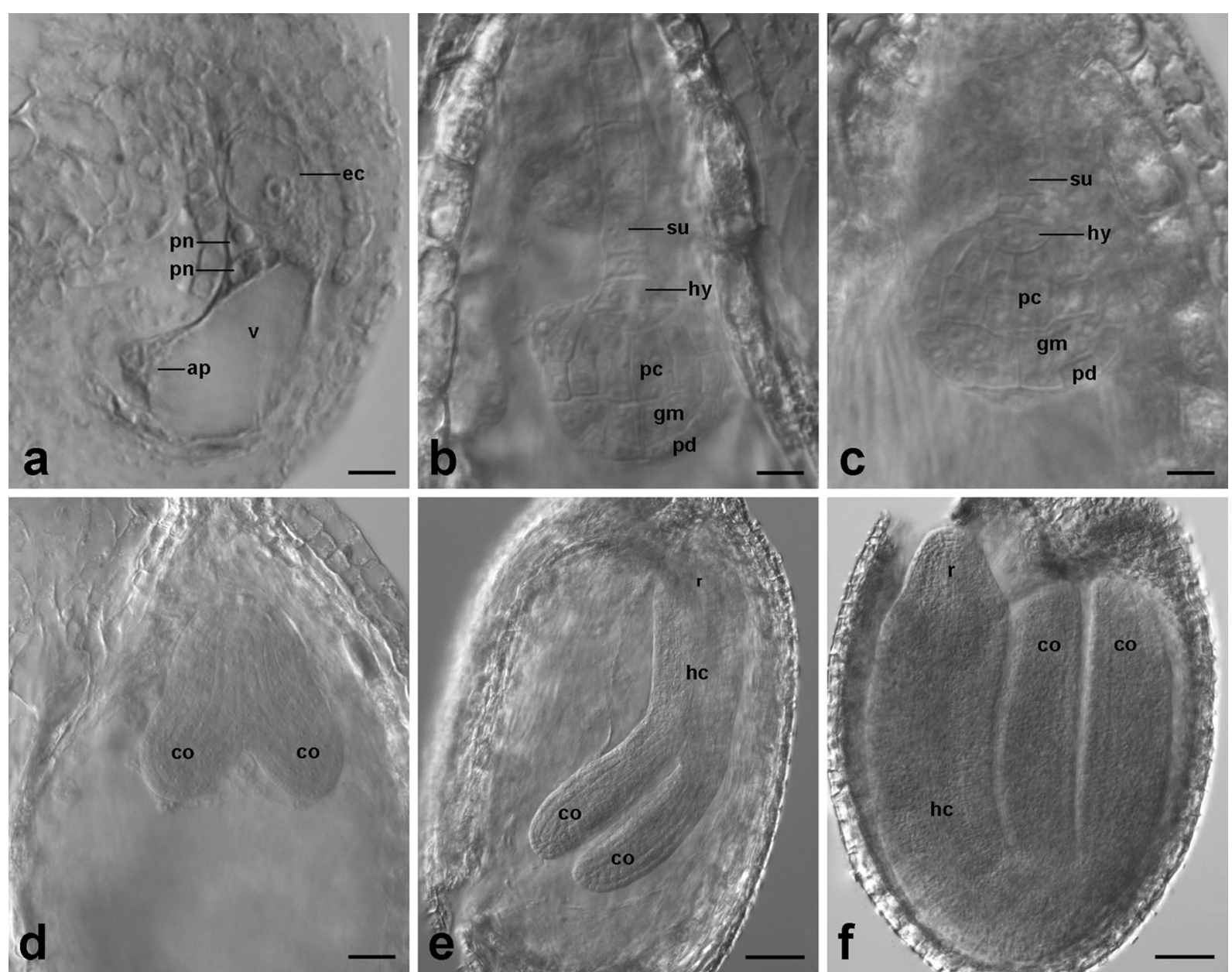

Fig. 1 Differential interference contrast (DIC) images of Arabidopsis thaliana ovules cleared by the standard procedure with prolonged incubation time in pure methyl salicylate up to 4 weeks. a Mature embryo sac with a central cell before polar nuclei fusion. $\mathbf{b}-\mathbf{f}$ Subsequent stages of embryogenesis. $\mathbf{b}$ Globular-shaped embryo. c Late globular-shaped embryo. The bilateral symmetry of the proper embryo begins to form. $\mathbf{d}$ Late heart-shaped embryo. e Walking-stick-shaped embryo. f Mature embryo. ap, antipodal cells; co, cotyledon; ec, egg cell; gm, ground meristem; $h c$, hypocotyl; hy, hypophysis; $p c$, procambium; $p d$, protoderm; $p n$, polar nucleus in the central cell; $r$, radicle; su, suspensor; $v$, vacuole. Scale bars: $10 \mu m$ $(\mathbf{a}-\mathbf{c}), 20 \mu \mathrm{m}(\mathbf{d}), 50 \mu \mathrm{m}(\mathbf{e}, \mathbf{f})$

\section{Discussion}

As the rapid development of microscopy techniques over the years has advanced, the ability to visualize plant tissues and cell structures has greatly increased. However, plant features limit their transparency to visible light, which prevents access to their internal structures [9]. Therefore, with the aim of obtaining images of better quality, numerous clearing protocols that render plant tissues or organs translucent without disturbing their anatomy have been described, of which the use of methyl salicylate as a clearing agent is very common for studying ovules (e.g. $[6,7,22,52,61]$. The clearing technique is a quick and simple method frequently used in classical embryology to analyze ovule development, embryo sac formation, embryogenesis, and seed development $[5,6$, $13,16,17]$. Moreover, it requires less effort than conventional embedding-sectioning procedures, that are arduous and time-consuming $[7,8]$.

We showed that the standard clearing procedure with methyl salicylate applied, according to Young et al. [6], with minor modifications by Musiał et al. [53], was an appropriate method to make the tenuinucellate ovules of $A$. thaliana and $B$. laevigata transparent. It was also suitable for clearing the crassinucellate ovules of $A$. maritima and $V$. banksii. However, this approach was insufficient for the crassinucellate ovules of $B$. vulgaris, where female gametophytes were only slightly visible after processing. This was due to the specific structure 

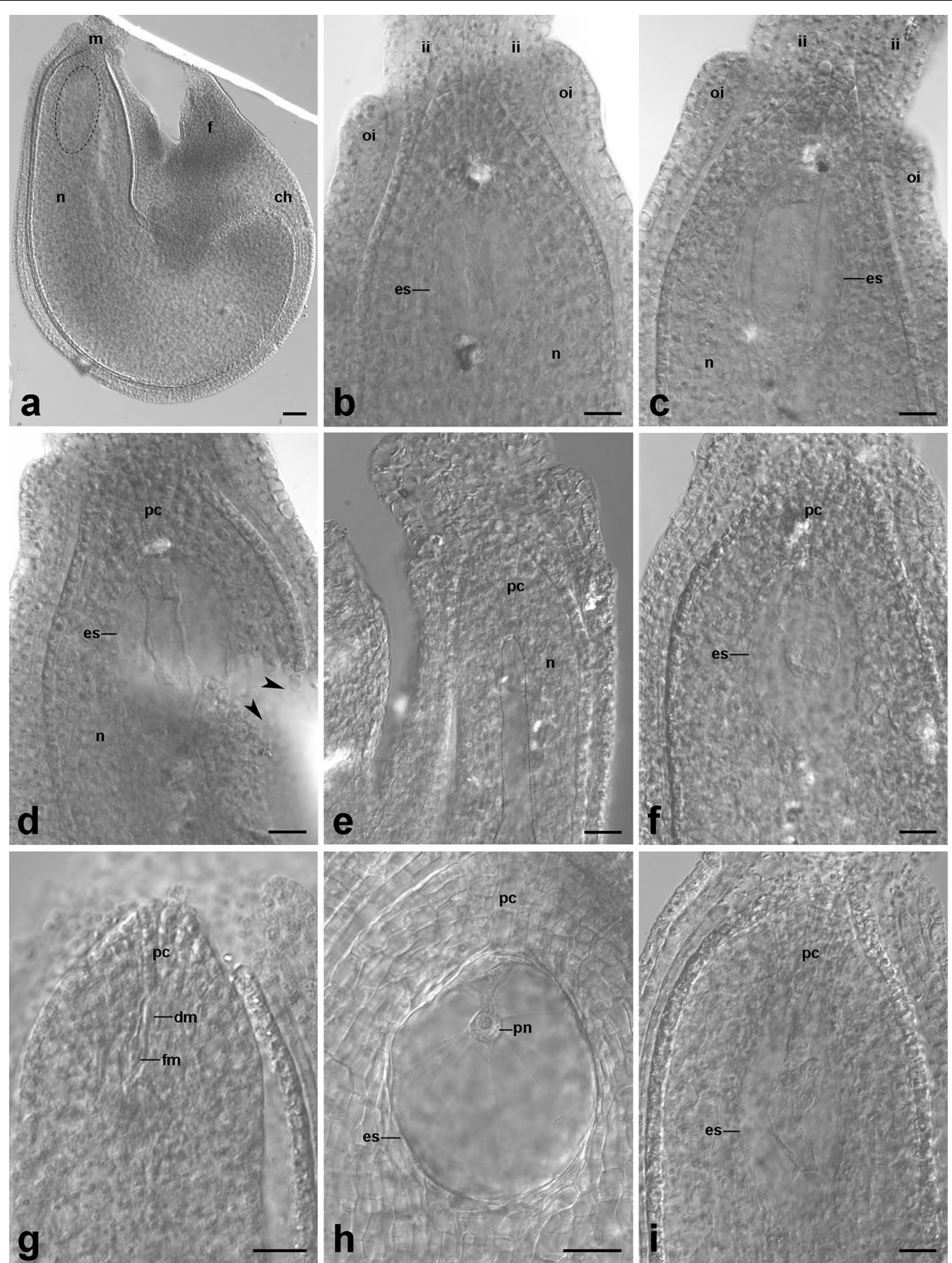

Fig. 2 Differential interference contrast (DIC) images of Beta vulgaris ovules cleared by the standard procedure with methyl salicylate (a), and the exemplary effects of its modifications tested (b-i). a Ovule with hardly visible embryo sac (dotted line). $\mathbf{b}$ Micropylar pole of the ovule with a mature embryo sac after the standard procedure with prolonged incubation time in pure methyl salicylate for up to 4 weeks. c Ovule with a mature embryo sac subjected to shaking and vacuuming during infiltration steps. d Needle-disrupted ovule (arrowheads) with a mature embryo sac. e Over-macerated ovule with constricted embryo sac after pre-treatment with $6 \%$ hydrogen peroxide. $\mathbf{f}$ Well cleared ovule after pre-treatment with $3 \%$ sulfuric acid. Image quality distorted by light reflection. $\mathbf{g}-\mathbf{i}$ Well cleared ovules after pre-treatment with $0.1 \mathrm{M}$ hydrochloric acid combined with Schiff's reagent. $\mathbf{g}$ Ovule after meiosis with a functional megaspore formed. $\mathbf{h}$ Mature embryo sac with visible polar nucleus of the central cell. i Mature embryo sac. ch, chalazal pole of the ovule; $d m$, degenerated megaspore; es, embryo sac; $f$, funiculus; fm, functional megaspore; ii, inner integument; $m$, micropylar pole of the ovule; $n$, nucellus; oi, outer integument; $p c$, parietal cells; $p n$, polar nucleus of the central cell. Scale bars: $20 \mu \mathrm{m}(\mathbf{b}-\mathbf{i}), 50 \mu \mathrm{m}(\mathbf{a})$ 

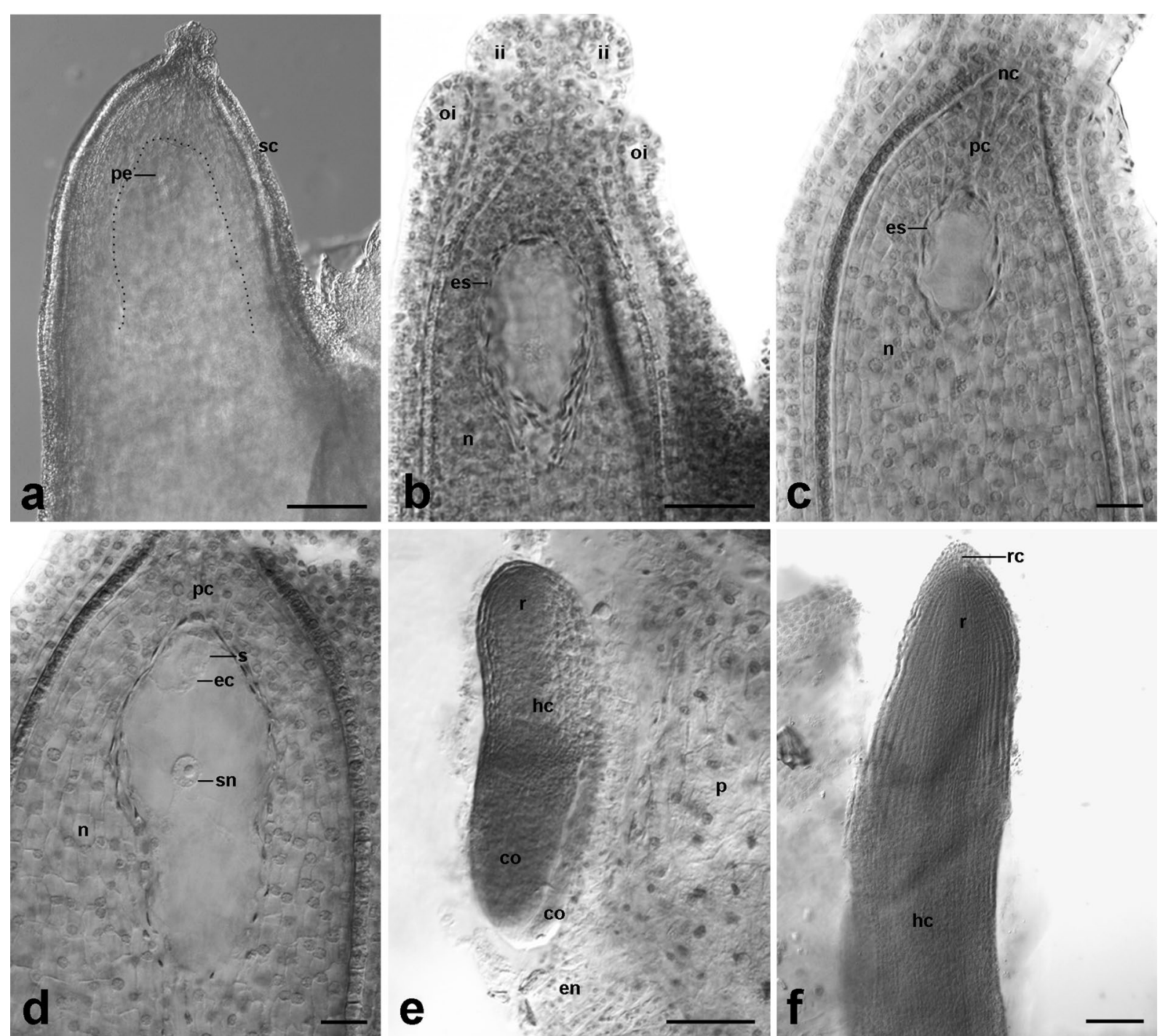

Fig. 3 Differential interference contrast (DIC) images of Beta vulgaris ovules cleared by the modified procedure. The material was pre-treated with $1 \mathrm{M}$ hydrochloric acid combined with Schiff's reagent, and subjected to shaking and vacuuming during infiltration steps. a Ovule at post-fertilization stage. The proembryo in the embryo sac slightly visible due to the presence of the developing seed coat (negative control). $\mathbf{b}-\mathbf{f}$ Ovules after optimization of the modified procedure. $\mathbf{b}$ Ovule with an embryo sac. c Micropylar pole of the ovule with a young embryo sac. $\mathbf{d}$ Ovule with a mature embryo sac after polar nuclei fusion. e, $\mathbf{f}$ Before the maceration step with hydrochloric acid, the material was pre-treated with $95 \%$ sulfuric acid in order to manually remove the seed coat. e Torpedo-shaped embryo. f Apical part of a mature embryo with embryonic tissues of hypocotyl and radicle surrounded by a root cap. $\mathbf{b}-\mathbf{d}$ Pre-fertilization stages; $\mathbf{a}, \mathbf{e}, \mathbf{f}$ post-fertilization stages. Black dotted line surrounds an embryo sac. co, cotyledon; ec, egg cell; en, cellular endosperm; es, embryo sac; hc, hypocotyl; ii, inner integument; $n$, nucellus; $n c$, nucellar cap; oi, outer integument; $p$, perisperm; $p c$, parietal cells; pe, proembryo; $r$, radicle; $r c$, root cap; s, synergid; $s c$, seed coat; sn, secondary nucleus of the central cell. Scale bars: $20 \mu \mathrm{m}(\mathbf{c}, \mathbf{d}), 50 \mu \mathrm{m}(\mathbf{b}), 100 \mu \mathrm{m}(\mathbf{a}, \mathbf{e}, \mathbf{f})$

of sugar beet ovules, i.e. the embryo sac location deep in the thick nucellar tissue surrounded by parietal cells and massive, multi-layered integuments, and by the presence of a nucellar cap at the micropylar pole. Moreover, in developing seeds, integuments form a hard and dark seed coat, that is rich in tannins, and a starchy perisperm occurs that disturbs analyses, as reported previously [3234, 44, 47, 48, 62]. The abovementioned features caused difficulties in penetration of the clearing mixtures into the internal tissues of the ovules. Hence, the search for a new protocol to clear the $B$. vulgaris ovules was necessary to enable a large-scale screening of developing ovules and seeds.

To date, embryological observations in the sugar beet have been conducted mostly by means of embedding-sectioning techniques [32, 33, 36, 38, 63]. To our knowledge, 


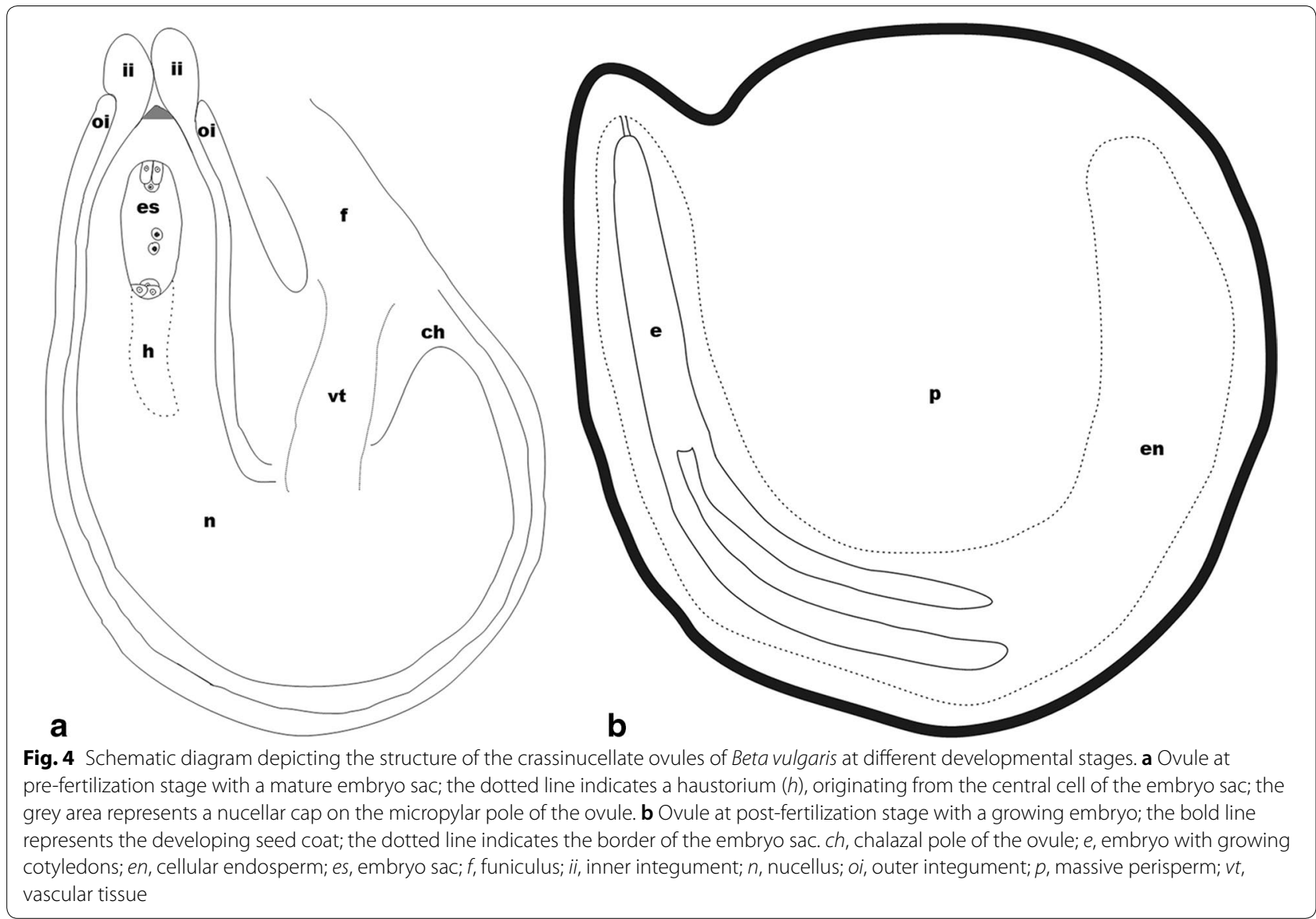

the only report published to date which addresses the use of clearing solution to observe sugar beet ovules is that by Ferrant and Bouharmont [38], who applied a modified stain-clearing technique by Stelly et al. [8] that involved Mayer's hemalum and methyl salicylate. However, the authors applied the clearing technique as complementary to the primary conventional one, which includes embedding, cutting and staining the material, which renders it a multi-step and, therefore, time-consuming approach, especially when analyzing many samples in a short time. Thus, unlike our protocol, their method is not suitable for large scale studies. Bearing in mind all the previous attempts, we aimed to apply the methyl salicylate-based clearing technique as the basic one to characterize a large amount of $B$. vulgaris ovules at different developmental stages. We have added numerous variants of the method that allowed us to select the best protocols for young ovules and for later stages of seed development in $B$. vulgaris.

In current literature, the clearing technique is routinely used in research on the ovule and seed development of the model plant $A$. thaliana, especially in the research on expression and in situ localization of genes in various mutants. In these studies, chloral hydrate, which is known to be toxic, is often used as the clearing agent (e.g. [49-51, 64]. We, therefore, suggest using methyl salicylate instead, which brought about good clearing results (Table 1; Additional file 2: Fig. S1). As we can conclude from our experiments, an even higher level of clarity is achieved by simply extending the incubation period in pure methyl salicylate (Fig. 1). Contemporary research on embryological processes, including observations of classical sexual reproduction stages as well as apomictic processes has been widely conducted using the clearing technique with methyl salicylate, as, for instance, in Rudbeckia bicolor [52], Agave tequilana [54], or Ranunculus auricomus [56]. Additionally, our observations also indicate that methyl salicylate may be applied to clear effectively the tennuinucellate ovules of $B$. laevigata, and the crassinucellate ovules of $A$. maritima and $V$. banksii.

Clearing crassinucellate ovules has always been problematic, not only because of the thick layers of the nucellus tissue, but also because of its starchy content, thick integuments and early seed coat formation. The study on apomixis in cassava (Manihot esculenta Cranz) is a good example of the problem [65]. The authors published 
molecular data (analysis with RAPD markers) along with anatomic studies to prove apomixis in this species, since pictures of the anatomic analyses conducted by clearing were not convincing. This case brings about another problem: the proper equipment to visualize the cleared objects and their proper documentation. When dealing with cleared whole-mount ovules, differential interference contrast (DIC) microscopy is a useful tool for observing their internal structures, as shown in this paper. However, some works in the literature suggest that a whole-mount eosin B-staining confocal laser scanning microscopy (WE-CLSM) may also be a promising method worth considering in future studies $[66,67]$. This approach is, moreover, also applicable with methyl salicylate, as documented by these authors, who used it for investigating abnormal embryo sacs in indica/japonica rice hybrids, as well as in similar studies by other authors (e.g. $[68,69])$.

After testing numerous modifications of the standard procedure, we established the most suitable approach for clearing the crassinucellate ovules of $B$. vulgaris at several developmental stages. Most of the modifications in the development of our protocol aimed to increase the accessibility of internal ovule structures to the clearing solution (methyl salicylate), which was obtained by (1) chemical softening of the tissues, (2) the use of a vacuum pump in order to infiltrate the internal ovule tissues with methyl salicylate, (3) the application of continuous gentle shaking throughout the incubation step with clearing mixtures, and (4) manual removal of the chemically softened seed coat. The results show the effectiveness of our method, making it possible to study the megagametoand embryogenesis of B. vulgaris (Fig. $3 \mathrm{~b}-\mathrm{f}$ ). The proposed protocol can be directly applied both to research and breeding programs to evaluate the development of gynogenic embryos in that species and thus to improve the breeding process of the crop of great economic importance.

\section{Conclusions}

In this study, we established an improved protocol for clearing the crassinucellate ovules of $B$. vulgaris, relying mainly on a novel combination of various pre-treatments increasing the accessibility of the tissue to methyl salicylate, which allowed us to investigate female gametophyte of the sugar beet and its embryo development. Many laboratories could substantially benefit from the results of our experiments. Especially the laboratories which rely on the routine microscopic analysis of sugar beet ovules, particularly while developing new protocols for haploid production. The presented clearing protocol may also provide a useful tool for further investigations on the flowering biology of the sugar beet and other species developing crassinucellate ovules, e.g. the cucumber, the evening primrose and others.

\section{Additional files}

Additional file 1: Table S1. Attempts to modify the standard clearing procedure applied to improve the transparency of the B. vulgaris ovules.

Additional file 2: Fig. S1. Differential interference contrast (DIC) images of Arabidopsis thaliana ovules in subsequent stages of development cleared by the standard procedure with methyl salicylate. (a) Fragment of an ovary with multiple ovules. (b) Young ovule with two-nucleate embryo sac. (c) Ovule with mature embryo sac. (d) Early torpedo-shaped embryo. (e) Late torpedo-shaped embryo. (f) Mature embryo. ch, chalazal pole of the ovule; co, cotyledon; ec, egg cell; en, cellular endosperm; ep, epidermis; es, embryo sac; $h c$, hypocotyl; ii, inner integument; oi, outer integument; $p$, plumule; r, radicle; $s c$, seed coat; $s n$, secondary nucleus of the central cell; su, suspensor. Scale bars: $10 \mu \mathrm{m}(\mathbf{b}, \mathbf{c}), 20 \mu \mathrm{m}(\mathbf{d}), 50 \mu \mathrm{m}(\mathbf{a}, \mathbf{e}, \mathbf{f})$.

Additional file 3: Fig. S2. Differential interference contrast (DIC) images of Armeria maritima (a), Biscutella laevigata (b), and Viola banksii (c) ovules cleared by the standard procedure with methyl salicylate. ap, antipodal cells; ea, egg apparatus; ec, egg cell; ii, inner integument; $n$, nucellus; oi, outer integument; pn, polar nucleus; s, synergid; sn, secondary nucleus of the central cell. Scale bars: $20 \mu \mathrm{m}$ (b), $50 \mu \mathrm{m}(\mathbf{a}, \mathbf{c})$.

\section{Acknowledgements}

The authors wish to thank Rebecca Thor and Urszula Pieniążek for providing sugar beet and Arabidopsis plants, respectively. We are grateful to Prof. Dariusz Grzebelus for his helpful suggestions on the manuscript.

\section{Authors' contributions}

Conceptualization: BD, EG, MK and MW; Methodology: MK and MW; Formal analysis: MK and DK; Investigation: MK and DK; Resources: BD, EG and MK; Writing —original draft: MK and DK; Writing_review \& editing: EG, DK, MK, MW and BD; Visualization: MK and DK; Supervision: EG; Project administration: EG; Founding acquisition: BD, MW and EG. All authors read and approved the final manuscript.

\section{Funding}

This research was financed by Syngenta Seeds AB (Sweden), Project No. BZ-928/WBiO/IBRiB/17-18, and the statutory funds for science granted by the Polish Ministry of Science and Higher Education to the Faculty of Biotechnology and Horticulture, University of Agriculture in Krakow.

\section{Availability of data and materials}

All data generated or analyzed during this study are included in this published article and its supplementary information files.

Ethics approval and consent to participate Not applicable.

\section{Consent for publication}

Not applicable.

\section{Competing interests}

The authors declare that they have no competing interests.

\section{Author details}

${ }^{1}$ Department of Plant Cytology and Embryology, Institute of Botany, Jagiellonian University, Gronostajowa 9, 30-387 Kraków, Poland. ${ }^{2}$ Institute of Plant Biology and Biotechnology, Faculty of Biotechnology and Horticulture, University of Agriculture in Krakow, 29 Listopada 54, 31-425 Kraków, Poland. ${ }^{3}$ Institute of Biology, Pedagogical University of Cracow, Podchorążych 2, 30-084 Kraków, Poland. ${ }^{4}$ MariboHilleshög Research AB, Säbyholmsvägen 24, 26191 Landskrona, Sweden. 
Received: 14 May 2019 Accepted: 26 June 2019

Published online: 08 July 2019

\section{References}

1. Dohm JC, Minoche AE, Holtgräwe D, Capella-Gutiérrez S, Zakrzewski F, Tafer H, Rupp O, Sörensen TR, Stracke R, Reinhardt R, Goesmann A, Kraft T, Schulz B, Stadler PF, Schmidt T, Gabaldón T, Lehrach H, Weisshaar B, Himmelbauer $\mathrm{H}$. The genome of the recently domesticated crop plant sugar beet (Beta vulgaris). Nature. 2014;505:546-9.

2. Gürel S, Gürel E, Kaya Z. Doubled haploid plant production from unpollinated ovules of sugar beet (Beta vulgaris L.). Plant Cell Rep. 2000;19:1155-9.

3. Aflaki F, Pazuki A, Gürel S, Stevanato P, Biancardi E, Gürel E. Doubled haploid sugar beet: an integrated view of factors influencing the processes of gynogenesis and chromosome doubling. Int Sugar J. 2018;120:274-85.

4. Pazuki A, Aflaki F, Gürel E, Ergül A, Gürel S. Gynogenesis induction in sugar beet (Beta vulgaris) improved by 6-benzylaminopurine (BAP) and synergized with cold pretreatment. Sugar Tech. 2018;20(1):69-77.

5. Herr JM. A new clearing-squash technique for the study of ovule development in angiosperms. Am J Bot. 1971;58:785-90.

6. Young BA, Sherwood RT, Bashaw EC. Cleared-pistil and thick-sectioning techniques for detecting aposporous apomixis in grasses. Can J Bot. 1979;57:1668-72.

7. Jongedijk E. A rapid methyl salicylate clearing technique for routine phase-contrast observations of female meiosis in Solanum. J Microsc. 1987; 146:157-62.

8. Stelly DM, Peloquin SJ, Palmer RG, Crane CF. Mayer's hemalum-methyl salicylate: a stain-clearing technique for observations within whole ovules. Stain Technol. 1984;59(3):155-61.

9. Timmers ACJ. Light microscopy of whole plant organs. J MicrosC. 2016;263(2):165-70

10. Fredrikson M. The development of the female gametophyte of Epipactis (Orchidaceae) and its inference for reproductive ecology. Am J Bot. 1992;79:63-8.

11. Herr JM. The use of Nomarski-interference microscopy for the study of structural features in cleared ovules. Acta Bot Indica. 1973;1:35-40.

12. Herr JM. A clearing-squash technique for the study of ovule development in angiosperms. In: Radford AE, Dickinson WC, Bell JR, editors. Vascular plant systematics. New York: HarperCollins; 1974. p. 230-5.

13. Herr JM. Recent advances in clearing techniques for study of ovule and female gametophyte development. In: Ottaviano E, Mulcahy DL, Sari Gorla M, Bergamini Mulcahy G, editors. Angiosperm pollen and ovules. New York: Springer; 1992. p. 149-54.

14. Prakash N, Herr JM. Embryological study of Glottidium vesicarium through the use of clearing technique. Phytomorphology. 1979;29:71-7.

15. Crane CF, Carman JG. Mechanisms of apomixis in Elymus rectisetus from eastern Australia and New Zeland. Am J Bot. 1987;72:477-96.

16. Harvey R, Smith B. Megasporogenesis and megagametogenesis of Cardamine parviflora L. (Brassicaceae). J Penn Acad Sci. 2013;87(3):120-4.

17. Lux A, Vaculík M, Kováč J. Improved methods for clearing and staining of plant samples. In: Yeung EC, Stasolla C, Sumner MJ, Huang BQ, editors. Plant microtechniques and protocols. Cham: Springer; 2015. p. 167-78.

18. Savidan Y, Carman JG, Dresselhaus T. The flowering of apomixis: from mechanisms to genetic engineering. Mexico D.F.: CIMMYT; 2001.

19. Debenham EM. A modified technique for microscopic examination of the xylem of whole plants or plant organs. Ann Bot. 1939;3(10):369-73.

20. Herr JM. Application of a new clearing technique for the investigation of vascular plant morphology. J Elisha Mitchell Sci Soc. 1972;88:137-43.

21. Lersten NR. Modified clearing method to show sieve tubes in minor veins of leaves. Stain Technol. 1986;61(4):231-4.

22. Ponitka A, Ślusarkiewicz-Jarzina A. Cleared-ovule technique used for rapid access to early embryo development in Secale cereale $\times$ Zea mays crosses. Acta Biol Cracov Bot. 2004;46:133-7.

23. Richardson DS, Lichtman JW. Clarifying tissue clearing. Cell. 2015;162:246-57.

24. Wilkinson LG, Tucker MR. An optimised clearing protocol for the quantitative assessment of sub-epidermal ovule tissues within whole cereal pistils. Plant Methods. 2017;13(67):1-10.
25. Crane CF. Apomixis and crossing incompatibilities in some Zephyrantheae. Ph.D. Thesis, University of Texas, Austin, USA; 1978.

26. Sporne KR. A note on a rapid clearing technique of wide application. New Phytol. 1948;47:290-1.

27. Janes BS. Leaf-clearing technique to assist fungal spore germination counts. Nature. 1962;193:1099-100.

28. Schmid R. Floral anatomy of Myrtaceae. I. Syzygium. Bot Jahr Syst. 1972;92:433-89.

29. Anderson LE. Hoyer's solution as a rapid permanent mounting medium for bryophytes. Bryologist. 1954;57(3):242-4.

30. Zhou C, Yang HY. Enzymatic isolation of embryo sacs in angiosperms: isolation and microscopical observation on fixed materials. Acta Bot Sin. 1982;24:403-7.

31. Villani TS, Koroch AR, Simon JE. An improved clearing and mounting solution to replace chloral hydrate in microscopic applications. Appl Plant Sci. 2013;1(5):1300016.

32. Bruun $L$. The mature embryo sac of the sugar beet, Beta vulgaris: a structural investigation. Nord J Bot. 1987;7(5):543-51.

33. Bruun $L$, Olsen P. A structural investigation of the ovule in sugar beet, Beta vulgaris: the micropylar nucellus. Nord J Bot. 1989;9(1):81-7.

34. Olsen $P$, Bruun L. A structural investigation of the ovule in sugar beet, Beta vulgaris: integuments and micropyle. Nord J Bot. 1990;9(5):499-506

35. Barański R. In vitro gynogenesis in red beet (Beta vulgaris L.): effects of ovule culture conditions. Acta Soc Bot Pol. 1996:65(1-2):57-60.

36. Bossoutrot D, Hosemans D. Gynogenesis in Beta vulgaris L.: from in vitro culture of unpollinated ovules to the production of doubled haploid plants in soil. Plant Cell Rep. 1985;4:300-3.

37. Doctrinal M, Sangwan RS, Sangwan-Norreel BS. In vitro gynogenesis in Beta vulgaris L.: effects of plant growth regulators, temperature, genotypes and season. Plant Cell Tiss Org. 1989;17:1-12.

38. Ferrant V, Bouharmont J. Origin of gynogenetic embryos of Beta vulgaris L. Sex Plant Reprod. 1994;7:12-6.

39. Hosemans D, Bossoutrot D. Induction of haploid plants from in vitro culture of unpollinated beet ovules (Beta vulgaris L.). Z Pflanzenzucht 1983:91:74-7.

40. Lux H, Herrmann L, Wetzel C. Production of haploid sugar beet (Beta vulgaris L.) by culturing unpollinated ovules. Plant Breed. 1990;104:177-83.

41. Van Geyt J, Speckmann GJ, D'Halluin K, Jacobs M. In vitro induction of haploid plants from unpollinated ovules and ovaries of the sugarbeet (Beta vulgaris L.). Theor Appl Genet. 1987:73:920-5.

42. TeKrony D.M. Seed development and germination of monogerm sugar beet (Beta vulgaris L.) as affected by maturity. Ph.D. Thesis, Oregon State University, Corvallis, USA; 1969.

43. Szkutnik T. Apomixis in the sugar beet reproduction system. Acta Biol Cracov Bot. 2010;52(1):87-96.

44. Artschwager E. Development of flowers and seed in the sugar beet. J Agric Res. 1927;34:1-25

45. Artschwager E. Micro- and macrosporogenesis in sugar beet with special reference to the problem of incompatibility. Mem Hort Soc NY. 1927;3:295-7.

46. Artschwager $\mathrm{E}$, Starett RC. The time factor in fertilization and embryo development in the sugar beet. J Agric Res. 1933;47:823-43.

47. Davis GL. Systematic embryology of the angiosperms. New York: Wiley; 1966.

48. Johri BM, Ambegaokar KB, Srivastava PS. Comparative embryology of angiosperms. Berlin: Springer; 1992.

49. Ceccato L, Masiero S, Sinha Roy D, Bencivenga S, Roig-Villanova I, Ditengou FA, Palme K, Simon R, Colombo L. Maternal control of PIN1 is required for female gametophyte development in Arabidopsis. PLOS ONE. 2013;8(6):e66148

50. Grini PE, Jürgens G, Hülskamp M. Embryo and endosperm development is disrupted in the female gametophytic capulet mutants of Arabidopsis. GSA. 2002;162:1911-25.

51. Huck N, Moore JM, Federer M, Grossniklaus U. The Arabidopsis mutant feronia disrupts the female gametophytic control of pollen tube reception. Development. 2003;130:2149-59.

52. Musiał K, Kościńska-Pająk M, Sliwinska E, Joachimiak AJ. Developmental events in ovules of the ornamental plant Rudbeckia bicolor Nutt. Flora. 2012:207:3-9. 
53. Musiał K, Kościńska-Pająk M, Antolec R, Joachimiak AJ. Deposition of callose in young ovules of two Taraxacum species varying in the mode of reproduction. Protoplasma. 2015;252:135-44.

54. González-Gutiérrez AG, Gutiérrez-Mora A, Rodríguez-Garay B. Embryo sac formation and early embryo development in Agave tequilana (Asparagaceae). Springerplus. 2014;3:575.

55. Delgado L, Galdeano F, Sartor ME, Quarin CL, Espinoza F, Ortiz JPA. Analysis of variation for apomictic reproduction in diploid Paspalum rufum. Ann Bot. 2014:113:1211-8.

56. Barke $B H$, Daubert $M$, Hörandl E. Establishment of apomixis in diploid $F_{2}$ hybrids and inheritance of apospory from $F_{1}$ to $F_{2}$ hybrids of the Ranunculus auricomus complex. Front Plant Sci. 2018;9:1111.

57. Abdelbar $\mathrm{OH}$. Flower vascularization and fruit developmental anatomy of quinoa (Chenpodium quinoa Willd) Amaranthaceae. AOAS. 2018;63:67-75

58. Ozkaya A, Ciftci H, Yilmaz O, Tel AZ, Cil E, Cevrimli BS. Vitamin, trace element, and fatty acid levels of Vitex agnus-castus L., Juniperus oxycedrus L., and Papaver somniferum L. plant seeds. J Chem. 2013;2013:845743.

59. Wilms HJ. Development and composition of the spinach ovule. Acta Bot Neerl. 1980;29(4):243-60.

60. Pedersen B, Kalinowski LS, Eggum BO. The nutritive value of amaranth grain (Amaranthus caudatus). Plant Foods Hum Nutr. 1987;36:309-24.

61. Chuda A, Kłosowska K, Adamus A. Morphological, cytological and embryological characterization of $F_{1}$ A. cepa $\times$ A. roylei hybrids. Acta Biol Cracov Bot. 2015;57(2):98-105

62. Coumans M, Côme D, Gaspar T. Stabilized dormancy in sugarbeet fruits. I. Seed coats as a physicochemical barrier to oxygen. Bot Gaz. 1976;137:274-8.

63. Bruun L. Histological and semi-quantitative approaches to in vitro cellular responses of ovule, embryo and endosperm in sugar beet, Beta vulgaris L. Sex Plant Reprod. 1991;4:64-72.
64. Yadegari R, de Paiva GR, LauxT, Koltunow AM, Apuya N, Zimmerman $J \mathrm{~L}$, Fischer RL, Harada JJ, Goldberg RB. Cell differentiation and morphogenesis are uncoupled in Arabidopsis raspberry embryos. Plant Cell. 1994;6:1713-29.

65. Nassar NMA, Vieira MA, Vieira C, Grattapaglia D. A molecular and embryonic study of apomixis in cassava (Manihot esculenta Crantz). Euphytica. 1998;102:9-13.

66. Hu CY, Zeng YX, Lu YG, Li JQ, Liu XD. High embryo sac fertility and diversity of abnormal embryo sacs detected in autotetraploid indica/japonica hybrids in rice by whole-mount eosin B-staining confocal laser scanning microscopy. Plant Breed. 2009;128:187-92.

67. Zeng YX, Hu CY, Lu YG, Li JQ, Liu XD. Diversity of abnormal embryo sacs in indica/japonica hybrids in rice demonstrated by confocal microscopy of ovaries. Plnat Breed. 2007;126:574-80.

68. Fu XL, Lu YG, Liu XD, Li JQ. Crossability barriers in the interspecific hybridization between Oryza sativa and O. meyeriana. J Integr Plant Biol. 2009;51(1):21-8.

69. Shahid MQ, Jianfan S, Changmin W, Peng Z, Xiang-Dong L. Studies on the abnormality of embryo sac and pollen fertility in autotetraploid rice during different growing seasons. Pak J Bot. 2010;42(1):7-19.

\section{Publisher's Note}

Springer Nature remains neutral with regard to jurisdictional claims in published maps and institutional affiliations.
Ready to submit your research? Choose BMC and benefit from:

- fast, convenient online submission

- thorough peer review by experienced researchers in your field

- rapid publication on acceptance

- support for research data, including large and complex data types

- gold Open Access which fosters wider collaboration and increased citations

- maximum visibility for your research: over $100 \mathrm{M}$ website views per year

At $\mathrm{BMC}$, research is always in progress.

Learn more biomedcentral.com/submissions 